\title{
ORIGINAL ARTICLE Preclinical safety and tolerability of a repeatedly administered human leishmaniasis DNA vaccine
}

\author{
O Riede ${ }^{1}$, K Seifert ${ }^{2}$, D Oswald ${ }^{1}$, A Endmann ${ }^{1}$, C Hock $^{3}$, A Winkler ${ }^{4}$, FJ Salguero ${ }^{5,6}$, M Schroff ${ }^{1}$, SL Croft $^{2}$ and C Juhls ${ }^{1}$
}

\begin{abstract}
The leishmaniases are a complex of vector-borne diseases caused by protozoan parasites of the genus Leishmania. LEISHDNAVAX is a multi-antigen, T-cell epitope-enriched DNA vaccine candidate against human leishmaniasis. The vaccine candidate has been proven immunogenic and showed prophylactic efficacy in preclinical studies. Here, we describe the safety testing of LEISHDNAVAX in naive mice and rats, complemented by the demonstration of tolerability in Leishmania-infected mice. Biodistribution and persistence were examined following single and repeated intradermal (i.d.) administration to rats. DNA vectors were distributed systemically but did not accumulate upon repeated injections. Although vector DNA was cleared from most other tissues within 60 days after the last injection, it persisted in skin at the site of injection and in draining lymph nodes. Evaluation of single-dose and repeated-dose toxicity of the vaccine candidate after i.d. administration to naive, non-infected mice did not reveal any safety concerns. LEISHDNAVAX was also well tolerated in Leishmania-infected mice. Taken together, our results substantiate a favorable safety profile of LEISHDNAVAX in both naive and infected animals and thus, support the initiation of clinical trials for both preventive and therapeutic applications of the vaccine.
\end{abstract}

Gene Therapy (2015) 22, 628-635; doi:10.1038/gt.2015.35

\section{INTRODUCTION}

The leishmaniases are a complex of diseases caused by protozoan parasites of the genus Leishmania with up to 1.6 million cases reported worldwide annually ${ }^{1}$ and $\sim 350$ million people at risk to develop leishmaniasis. ${ }^{2}$ It is estimated that the most severe form, visceral leishmaniasis (VL), causes up to 40000 deaths per year. ${ }^{1}$ Measures to control transmission of the parasite were of limited success to date. Despite advances in treatment of VL over the last decade, drug toxicity and heat stability, difficult routes of administration and variation in drug efficacy between endemic areas remain issues to be fully solved. A preventive and therapeutic leishmaniasis vaccine prospectively represents the most cost-effective and successful measure to control the leishmaniases worldwide. ${ }^{3}$

Immunity to the intracellular parasite Leishmania is associated with T-cell-mediated immune responses. ${ }^{4}$ DNA vaccines are particularly able to deliver antigens into the major histocompatibility complex class I processing pathway, thereby inducing CD8 cytotoxic T-cell immune responses, ${ }^{5,6}$ necessary for clearance of Leishmania. In addition, CD4 T cells and B cells are activated by DNA vaccines. Hence, this vaccination technology is a promising approach for developing a leishmaniasis vaccine.

An appropriate preclinical safety profile of a vaccine candidate has to be established prior to initiation of clinical phase 1 studies. The US Food and Drug Administration (FDA) and the World Health Organization recommend the evaluation of distribution and persistence of DNA vaccines as well as their local reactogenicity and systemic toxicity. ${ }^{8,9}$ Results of corresponding studies suggest that DNA vaccines are safe, ${ }^{10,11}$ which has been confirmed in several clinical trials. ${ }^{12}$ However, immunogenicity of DNA vaccines was often modest in humans, necessitating better delivery methods and improved vaccine antigen expression. ${ }^{12}$ In addition, safety concerns prompted avoidance of antibiotic resistance genes and other selection markers for plasmid propagation. ${ }^{13}$ State-of-the-art plasmids are consequently more efficacious, safer and smaller than classical plasmids. ${ }^{14}$ Minimalistic Immunogenically Defined Gene Expression (MIDGE) vectors represent one of the most rigorous concepts for improvement. ${ }^{15}$ MIDGE vectors are small linear double-stranded DNA (dsDNA) molecules, solely containing sequences required for their function in vivo and no bacterial plasmid backbone sequences as they have been shown to negatively impact transgene expression and immunogenicity. ${ }^{16,17}$ MIDGE-Th1 vectors are MIDGE vectors with a short peptide (PKKKRKVEDPYC) covalently attached, enhancing the immune responses to encoded antigens. ${ }^{18,19}$ Recently, preclinical data on biodistribution and toxicity of MIDGE and MIDGE-Th1 vectors have been published, ${ }^{20,21}$ indicating an excellent safety profile after a single administration.

LEISHDNAVAX is a mixture of five MIDGE-Th1 vectors each encoding a different Leishmania antigen: KMP11, CPA, CPB, P74 (elongation factor 1-alpha) or TSA.22 Antigen selection and sequence design followed a novel rational approach. In a series of animal experiments it was demonstrated that LEISHDNAVAX is immunogenic and effective against challenge with Leishmania donovani, the causative agent of VL. ${ }^{22}$ The vaccine is aimed to be administered to humans in both preventive and therapeutic settings.

Here, we present comprehensive preclinical safety and tolerability data for LEISHDNAVAX. A repeated-dose toxicity study in naive mice and a biodistribution and persistence study in rats were performed. Moreover, the effect of LEISHDNAVAX

${ }^{1}$ MOLOGEN AG, Berlin, Germany; ${ }^{2}$ Faculty of Infectious and Tropical Diseases, London School of Hygiene \& Tropical Medicine, London, UK; ${ }^{3}$ IMGM Laboratories GmbH, Martinsried, Germany; ${ }^{4}$ LPT Laboratory of Pharmacology and Toxicology GmbH \& Co. KG, Hamburg, Germany and ${ }^{5}$ Animal Health and Veterinary Laboratories Agency, New Haw, Addlestone, UK. Correspondence: Dr C Juhls, Translational Research, MOLOGEN AG, Fabeckstraße 30, Berlin 14195, Germany.

E-mail: juhls@mologen.com

${ }^{6}$ Current address: School of Veterinary Medicine, University of Surrey, Guildford, GU2 7TE.

Received 3 November 2014; revised 20 February 2015; accepted 27 March 2015; accepted article preview online 14 April 2015 ; advance online publication, 30 April 2015 
administration on parasite burden and standard tolerability parameters in mouse models of VL were evaluated. In all studies, potential cumulative effects of repeated dosing of LEISHDNAVAX were addressed to allow for a better risk-assessment prior to multi-dose clinical trials.

\section{RESULTS}

LEISHDNAVAX is systemically distributed after intradermal administration

Biodistribution of the vaccine was assessed in rats after intradermal (i.d.) injection of a $120 \mu \mathrm{g}$ dose. Total DNA was extracted from tissue samples taken $24 \mathrm{~h}$ post injection and MIDGE-Th1 vector DNA quantified using a quantitative PCR (qPCR) assay. Vector DNA was found in a varying number of animals per group and in all tissues except for bone marrow (Figure 1a). The vector copy numbers per $\mu \mathrm{g}$ total DNA ranged from $4.04 \times 10^{3}$ (geometric mean, ovaries, $4 / 5$ animals positive) to $2.55 \times 10^{9}$ (geometric mean, skin of injection site, all animals positive).

Comparable distribution pattern after single or repeated administration

Next, we tested whether repeated administration alters the distribution pattern or causes accumulation of vector DNA in tissues. One hundred and twenty micrograms of LEISHDNAVAX were administered to rats i.d. at the same site four times at weekly intervals. Vector DNA was quantified in total DNA extracted from tissue samples collected $24 \mathrm{~h}$ after the last injection. Distribution patterns and amounts of vector DNA were comparable $24 \mathrm{~h}$ after single and repeated injection (Figures $1 \mathrm{a}$ and b). Copy numbers per $\mu \mathrm{g}$ total DNA ranged from $4.63 \times 10^{3}$ (geometric mean, lung tissue, $5 / 10$ animals positive) to $4.50 \times 10^{7}$ (geometric mean, skin of injection site, all animals positive).

MIDGE-Th1 vectors persist at injection site and in draining lymph nodes

Persistence of MIDGE-Th1 vectors was examined 14 days and 60 days post treatment. Fourteen days after four injections LEISHDNAVAX was cleared from the majority of organs (Figure 1c). High vector copy numbers per $\mu \mathrm{g}$ total DNA were found in skin of injection site (all animals positive, geometric mean: $3.45 \times 10^{6}$ copies) and in inguinal lymph nodes (7/10 animals positive, geometric mean: $2.88 \times 10^{4}$ copies). Sixty days after four injections, MIDGE-Th1 vectors were cleared from most tissues but persisted in inguinal lymph nodes (5/10 animals positive, geometric mean: $1.44 \times 10^{4}$ copies) and skin of injection site (all animals positive, geometric mean: $6.93 \times 10^{5}$ copies) (Figure 1d). a

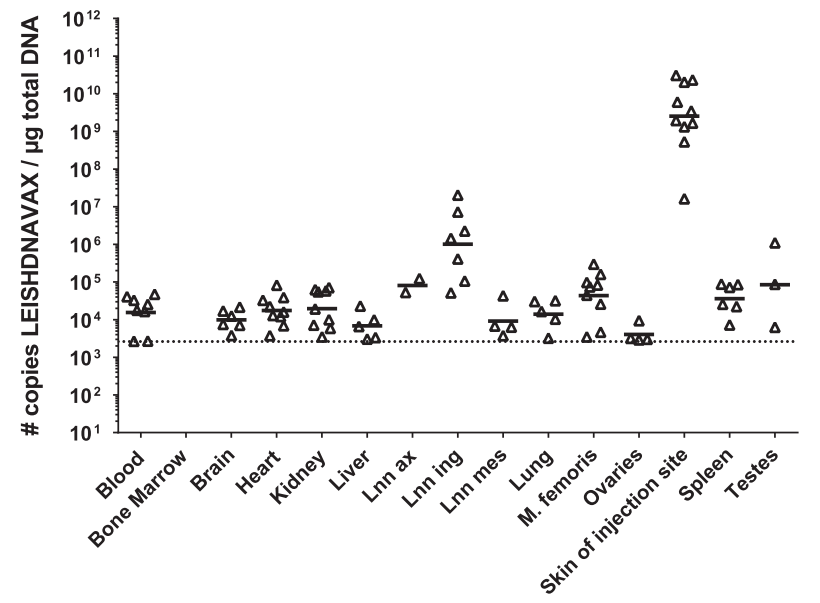

C

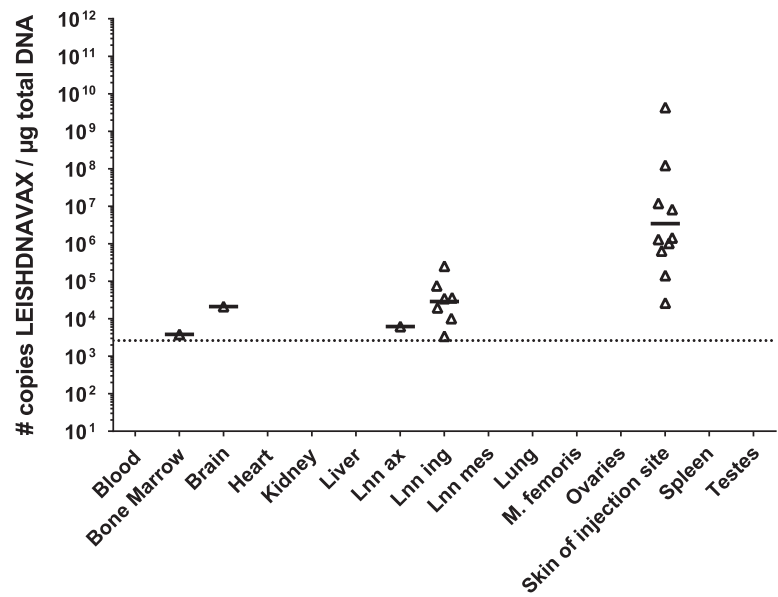

b

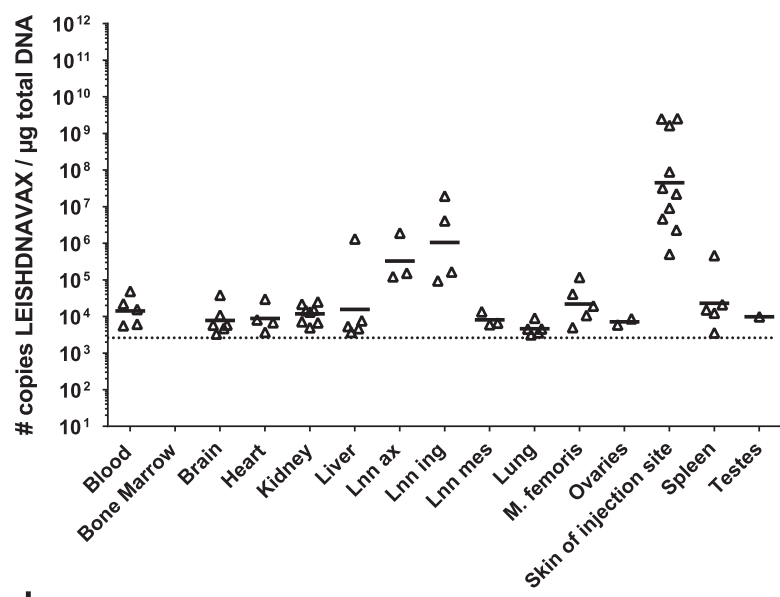

d

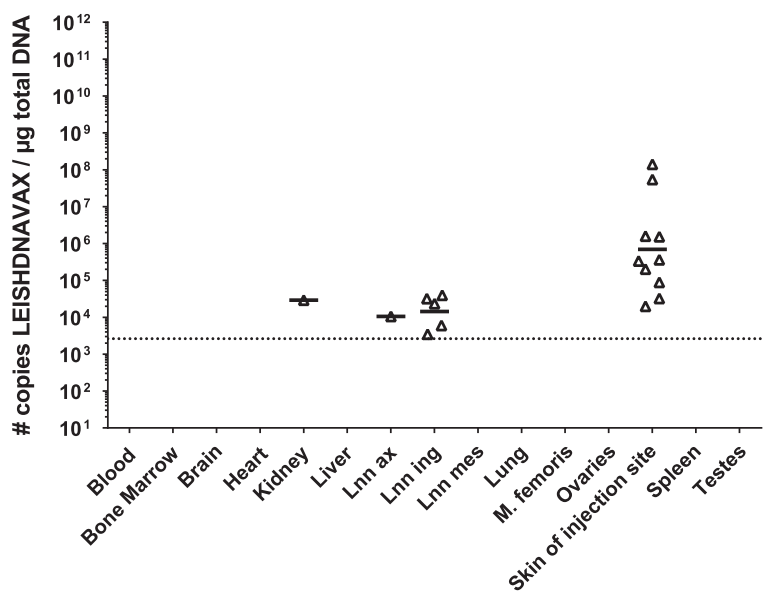

Figure 1. Biodistribution and persistence of LEISHDNAVAX following single and multiple i.d. injections. Groups of 10 Wistar rats (5 male, 5 female) were injected once (a) or four times in weekly intervals (b-d) with $120 \mu \mathrm{g}$ LEISHDNAVAX. Tissue samples were taken and processed $24 \mathrm{~h} \mathrm{(a}$ and $\mathbf{b}), 14$ days (c) or 60 days (d) after the last injection. Vector copy numbers were determined by qPCR. Single animal data and geometric mean values are given in log scale. Dotted lines indicate lower the limit of quantification LLOQ. Lnn ax: axillary lymph nodes; Lnn ing: inguinal lymph nodes; Lnn mes mesenteric lymph nodes; M. femoris: quadriceps muscle of thigh. 


\begin{tabular}{|lcccc}
\hline \multicolumn{4}{l}{ Table 1. Scheme of toxicity study in naive mice } \\
\hline $\begin{array}{l}\text { DNA dose } \\
(\mu g)\end{array}$ & $\begin{array}{c}\text { Number } \\
\text { of doses }\end{array}$ & $\begin{array}{c}\text { Day(s) of } \\
\text { immunization }\end{array}$ & $\begin{array}{c}\text { Day(s) of } \\
\text { sampling } \\
\text { after last dosing }\end{array}$ & $\begin{array}{c}\text { Number of } \\
\text { animals (males, } \\
\text { females) }\end{array}$ \\
\hline 10 & 1 & 1 & 1 & $10(5,5)$ \\
& 5 & $1,8,15,22,29$ & 1,14 & $20(10,10)$ \\
50 & $5^{\mathrm{b}}$ & $1,8,15,22,29$ & 1,14 & $20(10,10)$ \\
& 1 & 1 & 1 & $10(5,5)$ \\
100 & 5 & $1,8,15,22,29$ & 1,14 & $20(10,10)$ \\
& $5^{\mathrm{b}}$ & $1,8,15,22,29$ & 1,14 & $20(10,10)$ \\
Placebo & 1 & 1 & 1 & $10(5,5)$ \\
& 5 & $1,8,15,22,29$ & $1,14,61$ & $30(15,15)$ \\
& $5^{\mathrm{b}}$ & $1,8,15,22,29$ & $1,14,61$ & $30(15,15)$ \\
& 5 & $1,8,15,22,29$ & $1,14,61$ & $30(15,15)$ \\
& $5^{\mathrm{b}}$ & $1,8,15,22,29$ & $1,14,61$ & $30(15,15)$ \\
\hline
\end{tabular}

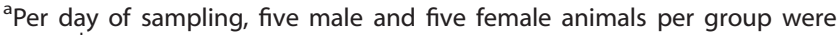
killed. ${ }^{b}$ Satellite group to assess biologic activity of the vaccine lot and induction of antibodies against dsDNA.

LEISHDNAVAX is well tolerated in naive animals

To assess toxicity of LEISHDNAVAX in naive mice, sterile phosphate-buffered saline (PBS, placebo) and ascending doses of the vaccine were injected either once or five times in weekly intervals (Table 1). LEISHDNAVAX was well tolerated at all doses tested. No animal died during the in-life phase, and no change in behavior or external appearance of the animals was noted. Comparing placebo-treated to LEISHDNAVAX-treated animals, no differences were observed in body weight, food and drinking water consumption, ophthalmological and auditory examinations, urinalysis, organ weights and the neurological screening. No local intolerance reactions were noted after single or repeated vaccine dosing. Minor deviations in single animals/groups for few blood parameters (large unstained cells, albumin/globulin ratio, aamylase) were classified as not vaccine-related. Macroscopic post mortem examination of organs revealed an enlarged spleen in a single male animal 1 day after single administration of $100 \mu \mathrm{g}$ LEISHDNAVAX, which possibly indicated the activation of the lymphatic system. In all animals the histological findings were within the normal range of variation. No LEISHDNAVAX-related morphological lesions were found. No signs of auto-immune reactions were observed, and there were no elevated levels of serum antibodies against dsDNA detected.

Biological activity of the vaccine lot was proven by induction of antigen-specific serum immunoglobulin $\mathrm{G}(\mathrm{IgG})$ in mice of satellite groups (Table 1). A dose-dependent increase of LEISHDNAVAXspecific IgG levels was observed (Figure 2), in line with data from efficacy studies as previously reported. ${ }^{22}$

Rats receiving the vaccine during the biodistribution study did not exhibit any vaccine-related local or systemic signs of toxicity, and also necropsy did not reveal any vaccine-related toxicity.

\section{LEISHDNAVAX is well tolerated in L. donovani-infected mice}

Tolerability of LEISHDNAVAX and effects on visceral parasite burden were evaluated in BALB/C and C57BL/6 mice. Groups of mice infected with $L$. donovani were injected with one, two or three doses of $100 \mu \mathrm{g}$ LEISHDNAVAX or PBS in weekly intervals. Parasite burden was evaluated seven days and 29 days after the last injection. No significant difference in hepatic or splenic parasite burden was found between groups receiving equal numbers of injections of PBS or LEISHDNAVAX. In both treatment groups infection with $L$. donovani followed the known kinetic ${ }^{23}$ with distinct organ-specific growth patterns in livers and spleens

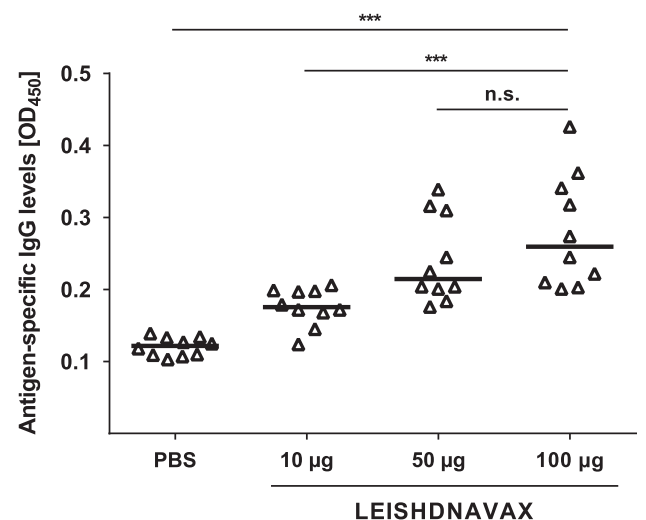

Figure 2. Immunogenicity of ascending LEISHDNAVAX doses in mice. Groups of 10 BALB/c mice ( 5 male, 5 female) were immunized i.d. at the tail base five times in weekly intervals with either PBS or LEISHDNAVAX (10, 50 or $100 \mu \mathrm{g}$ per dose). Fourteen days after the last immunization LEISHDNAVAX-specific antibodies (total lgG) in sera were quantified by ELISA using plates coated with a mixture of recombinant LEISHDNAVAX antigens. ${ }^{* *} P \leqslant 0.001$ (Student's $t$-test); n.s.: not significant.

of infected mice. Figure 3 shows the parasite burden as determined in the BALB/C and one $\mathrm{C} 57 \mathrm{BL} / 6$ experiment.

No significant difference in weights between PBS and LEISHDNAVAX-treated groups of mice was observed. Serum samples from mice, which had received three injections of PBS or LEISHDNAVAX, were subjected to analyses of standard biochemical parameters; alanine transaminase, aspartate aminotransferase, urea and creatinine. No significant differences between PBS and LEISHDNAVAX-treated groups were found for these parameters in BALB/C mice. Significant differences were found in levels of creatinine in C57BL/6 mice in two separate experiments. However, neither the time point nor the direction of difference were consistent between experiments (Table 2). Histological analysis of livers and spleens in repeated experiments and the kidney, heart and lung in a single experiment (C57BL/6 mice) revealed similar lesions in all animals (PBS and LEISHDNAVAX treated) in terms of location and severity. Lesions were consistent with infection and included severe granulomatous hepatitis and splenitis with intralesional parasites, granulomatous/interstitial pneumonia and interstitial nephritis and glomerulonephritis.

\section{DISCUSSION}

Biodistribution and persistence of DNA vaccines are studied to estimate the duration of antigen expression and the risk of vector integration into host genomic DNA., We examined the biodistribution of LEISHDNAVAX after a single and, in contrast to previously published results, ${ }^{20,21}$ also after a series of four injections at weekly intervals. This condensed application scheme is relevant for clinical approaches with: (i) a limited number of injections over a longer period of time as accepted for prophylactic vaccinations and (ii) vaccination regimes requiring more injections in shorter intervals, for example, therapeutic vaccinations. In line with recommendations of the US FDA, ${ }^{8}$ organ and tissue samples were taken at several time points following injections and vector DNA was quantified using quantitative PCR.

Twenty-four hour after single or repeated injection, MIDGE-Th1 vector DNA was detected in almost all organs and tissues examined, suggesting that it was distributed systemically, most likely via the lymphatic system and the blood stream. A similar distribution pattern has been described for MIDGE-Th1 vectors 
a

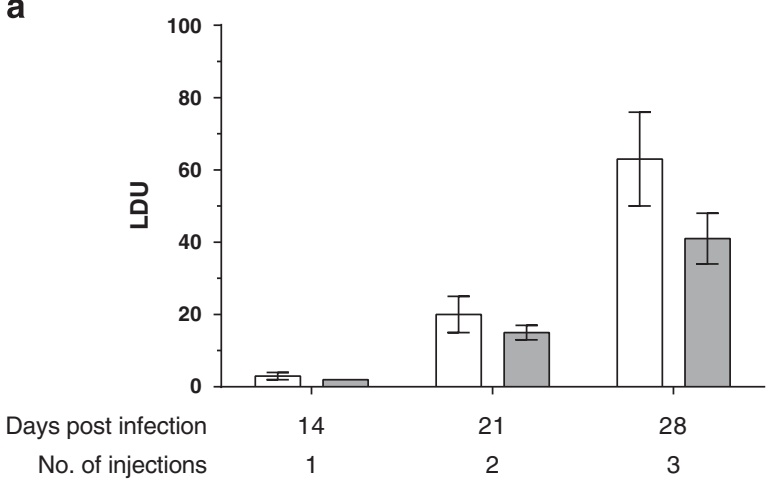

C

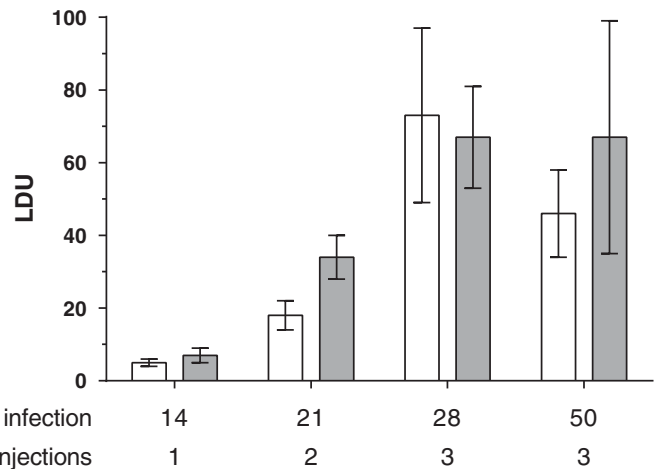

b

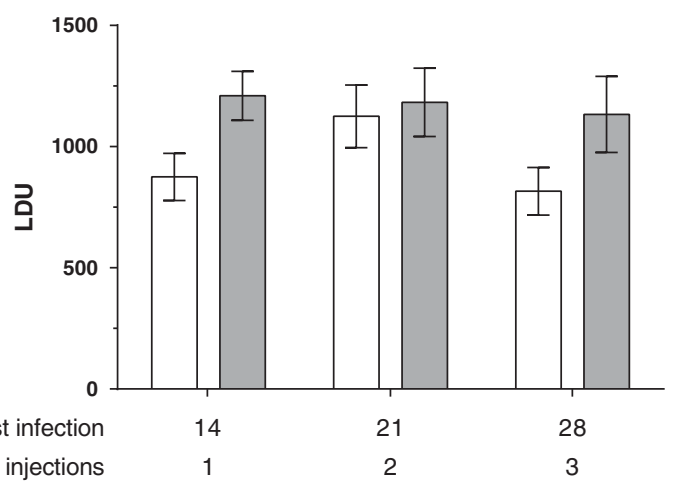

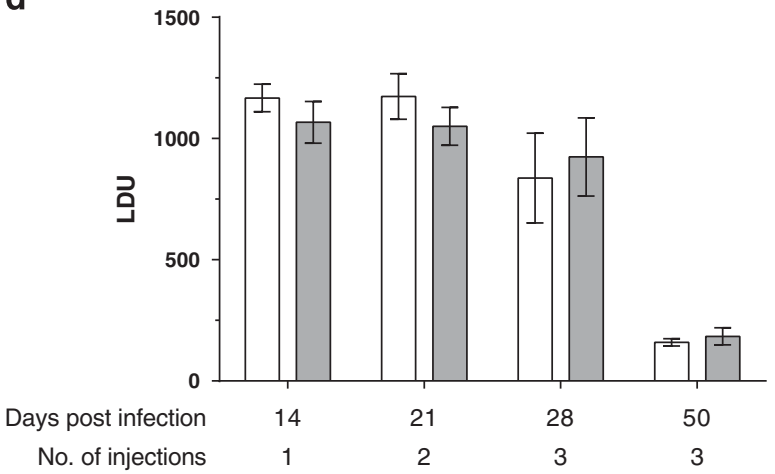

Figure 3. Parasite burden in BALB/C and C57BL/6 mice following administration of single and repeated doses of LEISHDNAVAX and PBS. Parasite burden expressed in Leishman-Donovan Units (LDU) is shown for BALB/c mice in spleens (a) and livers (b) ( $n=8-9$ mice per group) and for C57BL/6 mice in spleens (c) and livers (d) ( $n=4-8$ mice per group). Mice were infected on day 0, treated once (day 7$)$, twice (day 7 and 14) or three times (day 7, 14 and 21), respectively, with $100 \mu \mathrm{g}$ LEISHDNAVAX per dose or PBS. Parasite burden was determined 7 days after the last treatment and in addition, for two groups of C57BL/6 mice receiving either three LEISHDNAVAX or PBS injections, 29 days after the third treatment (day 50 post infection). White bars represent PBS-treated groups and dark gray bars LEISHDNAVAX-treated groups, error bars indicate s.e.m. Differences between groups were statistically not significant based on a one-way ANOVA followed by Bonferroni's multiple comparison's test, which compared groups that had received the same number of injections of PBS or LEISHDNAVAX $(P>0.05)$.

Table 2. Biochemical serum parameters of $L$. donovani-infected and PBS- or LEISHDNAVAX (DNA)-treated mice

\begin{tabular}{|c|c|c|c|c|c|c|c|}
\hline $\begin{array}{l}\text { Experiment/ } \\
\text { mouse strain }\end{array}$ & $\begin{array}{l}\text { Treatment } \\
\text { (3 doses) }\end{array}$ & $\begin{array}{l}\text { Sampling (days post } \\
\text { Infection) }\end{array}$ & Mice $\mathrm{n}$ & $\begin{array}{l}\text { Urea mean } \pm \text { s.e.m. } \\
\qquad\left(\mathrm{mmol}^{-1}\right)\end{array}$ & $\begin{array}{l}\text { Creatinine mean } \pm \text { s.e.m. } \\
\left(\mu \mathrm{mol} \mathrm{I}^{-1}\right)\end{array}$ & $\begin{array}{c}\text { ALT mean } \pm \text { s.e.m. } \\
\left(U I^{-1}\right)\end{array}$ & $\begin{array}{c}\text { AST mean } \pm \text { s.e.m. } \\
\left(U I^{-1}\right)\end{array}$ \\
\hline \multirow[t]{2}{*}{ 1/BALB/c } & PBS & 28 & 8 & $5.5 \pm 0.3$ & $9.6 \pm 0.8$ & $60.0 \pm 8.1$ & $90.0 \pm 35.7$ \\
\hline & DNA & 28 & 7 & $5.4 \pm 0.2$ & $11.7 \pm 1.9$ & $74.5 \pm 17.2$ & $194.6 \pm 103$ \\
\hline \multirow[t]{2}{*}{ 2/C57BL/6 } & PBS & 28 & 5 & $7.3 \pm 0.5$ & $18.0 \pm 0.9^{a}$ & $144.6 \pm 25$ & $176.1 \pm 35.5$ \\
\hline & DNA & 28 & 5 & $6.8 \pm 0.4$ & $13.4 \pm 1.2^{\mathrm{a}}$ & $122.0 \pm 16.2$ & $134.1 \pm 15.1$ \\
\hline \multirow[t]{4}{*}{ 3/C57BL/6 } & PBS & 28 & 8 & $6.2 \pm 0.2$ & $10.7 \pm 0.6$ & $142.8 \pm 13.7$ & $162.5 \pm 12.1$ \\
\hline & DNA & 28 & 7 & $5.6 \pm 0.3$ & $13.9 \pm 1.4$ & $156.6 \pm 20.1$ & $188.9 \pm 35.2$ \\
\hline & PBS & 50 & 7 & $7.0 \pm 0.4$ & $10.0 \pm 1.3^{\mathrm{a}}$ & $67.6 \pm 8.1$ & $90.4 \pm 10.9$ \\
\hline & DNA & 50 & 5 & $6.9 \pm 0.5$ & $14.3 \pm 1.2^{\mathrm{a}}$ & $57.6 \pm 6.2$ & $89.7 \pm 8.2$ \\
\hline
\end{tabular}

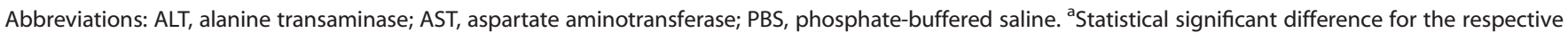
treatment groups/comparison, $P<0.05$.

encoding Hepatitis B surface antigen, ${ }^{21}$ indicating that distribution of MIDGE-Th1 vectors is independent of the encoded protein as previously reported for plasmid DNA vectors. ${ }^{11}$ Systemic distribution at early time points has also been shown for naked plasmid DNA upon i.m. and i.d administration. ${ }^{24,25}$ In accordance with other reports, ${ }^{11,26,27}$ the highest vector amounts were detected in samples taken from the site of injection. Consistently, lymph nodes draining the site of injection contained the second highest copy numbers, probably due to skin immune cells taking up DNA at the site of injection and migrating to the lymph nodes.
At day 14 after the fourth injection, vectors were cleared from nearly all organs except from skin and inguinal lymph nodes. Whereas the amount of vector DNA in skin samples was $\sim 10$-fold lower compared with $24 \mathrm{~h}$ after the last injection, vector copy numbers in inguinal lymph node samples were reduced $\sim 100$-fold. This finding is in line with reports on i.d.-administered plasmid DNA vaccines, ${ }^{27-29}$ suggesting that plasmids and MIDGE-Th1 vectors ( ${ }^{21}$ and this report) follow a similar pattern of distribution and persistence.

MIDGE-Th1 vector DNA was not cleared from skin and inguinal lymph nodes within 60 days after four injections. Although this 
was also observed following single i.d. administration of a MIDGETh1 vector encoding Hepatitis B surface antigen, ${ }^{21}$ it is in contrast to the finding that $50 \mu \mathrm{g}$ of tumor necrosis factor alpha-encoding MIDGE vector are cleared from the injection site and other tissues of mice within $24 \mathrm{~h}$ after intratumoral jet injection. ${ }^{20}$ This short time to overall clearance was probably related to wider dispersion of DNA upon multiple jet injection, the lower DNA concentration (five jet injections of $10 \mu \mathrm{g}$ DNA at $1 \mathrm{mg} \mathrm{ml}^{-1}$ versus one needle injection of $120 \mu \mathrm{g}$ DNA at $4 \mathrm{mg} \mathrm{ml}^{-1}$ ), as well as the rapid entry into the blood circuit due to the high vascularization and low retention rate of macromolecules in tumor tissue as compared with normal skin tissue. Though only a side-by-side comparison would be conclusive, we propose that these parameters strongly affected the time to overall clearance than the DNA dose. In fact, the rats in our study received up to $0.6 \mu \mathrm{g}$ LEISHDNAVAX DNA per gram body weight, thus a lower relative DNA dose than that administered to mice of the referenced study $(\sim 1.6 \mu \mathrm{g}$ tumor necrosis factor alpha MIDGE DNA per gram body weight). ${ }^{20}$

A persistence of at least 60 days as observed in our study suggests that vector DNA had entered long-living cells residing in the skin. Whether or not this vector DNA is still functioning cannot be concluded from our results, as the quantitative PCR method targeted a short consensus sequence only.

Notably, MIDGE-Th1 vector DNA did not accumulate in any tissue after repeated injections. At 60 days after one injection ${ }^{21}$ or after four injections of LEISHDNAVAX, comparable amounts of MIDGE-Th1 vector DNA were found, indicating that repeated injections do not enhance persistence. Therefore, future evaluations of biodistribution and persistence of MIDGE-Th1 vectors in similar settings can be based on a single injection.

Long-term persistence of vector DNA in tissues can be related to integration into host genomic DNA and thus, theoretically bears tumorigenic potential. However, published data show that the integration rate of plasmid DNA vectors does not exceed the rate of spontaneous mutation events within the host genome. ${ }^{26,27,30}$ Notably, for linear DNA vectors with a structure similar to MIDGE vectors a very low level of integration has been described. ${ }^{31}$ Furthermore and in contrast to closed circular plasmid DNA molecules, integration of covalently closed linear DNA constructs rather leads to disruption of chromosomes followed by apoptosis of affected cells, hence minimizing the risk of replicating unwanted genetic rearrangements. ${ }^{32}$ On the basis of these published results, the risk related to potential integration of MIDGE-Th1 vectors into host genomic DNA can be considered as low, though it was not assessed in this work.

In a repeated-dose toxicity study in naive mice, we tested three ascending doses of LEISHDNAVAX. The highest dose of $100 \mu \mathrm{g}$ corresponds to a human dose of $\sim 300 \mathrm{mg}$ DNA on a $\mathrm{mg} \mathrm{kg}^{-1}$ body weight base. Doses in published clinical trials ranged from $0.1 \mathrm{mg}^{33}$ to $4 \mathrm{mg}^{34}$ of plasmid DNA, so our study design includes a high safety margin. To further extend the safety margin, the vaccine was administered in a condensed schedule of five vaccinations (one more than the estimated maximum number for clinical application) in weekly intervals. Importantly, a No Observed Adverse Effect Level, that is, the highest dose without significant toxicity, was not reached with the doses tested. No local intolerance reactions related to the vaccine were observed. The results established in naive mice are corroborated by safety data obtained from the biodistribution study. Rats received $120 \mu \mathrm{g}$ LEISHDNAVAX, corresponding to a human dose of $\sim 24 \mathrm{mg}$ (based on $\mathrm{mg} \mathrm{kg}^{-1}$ body weight). There were no vaccine-related toxic effects observed either. Our results further confirm the findings of other investigators reporting excellent preclinical safety profiles of DNA vectors. ${ }^{10,11,20,26,27,30}$

In Leishmania-infected and diseased individuals, tolerability of the vaccine may be different than in healthy, naive vaccinees. Moreover, owing to the ability of Leishmania amastigotes to exploit host lgG as virulence factor, ${ }^{35}$ there is the theoretical risk of vaccine-related immune-enhancement of infection and pathogenesis as discussed for other infectious diseases. ${ }^{36,37}$ Hence demonstration of absence of disease exacerbation was included into the development program of LEISHDNAVAX. We evaluated the tolerability of LEISHDNAVAX in two different mouse strains, chosen for their inherent differences in cytokine responses to infection with $L$. donovani. ${ }^{38}$ These experiments demonstrate that LEISHDNAVAX had no effect on the kinetics of the parasite burden with no vaccine-related enhancement of infection at any of the time points investigated. The kinetic of infection corresponded to the well-documented pattern in mice with a rapid increase in hepatic parasite burden, followed by a decline in parasite numbers and clearance and a slower increase in parasite numbers in the spleen with the establishment of chronic infections. ${ }^{23}$ Results for all other standard parameters were similar for treated and nontreated mice, demonstrating a good tolerability of the vaccine candidate in infected animals.

In summary, we have shown here that LEISHDNAVAX, a novel DNA vaccine candidate against leishmaniasis is safe and well tolerated in both naive and Leishmania-infected mice. After repeated i.d. injections, the vaccine was rapidly cleared from most organs and tissues of rats and persisted in the skin of injection site and its draining lymph nodes only. We conclude that LEISHDNAVAX has a favorable safety profile that supports the initiation of human clinical trials.

\section{MATERIALS AND METHODS}

\section{Vaccine}

LEISHDNAVAX is an equimass mixture of five MIDGE-Th1 vectors, dissolved in sterile PBS. Each vector encodes one Leishmania antigen: KMP11, CPA CPB, P74 or TSA, respectively. Their DNA sequences and expression cassettes of MIDGE-Th1 vectors have been described previously. ${ }^{22}$ MIDGETh1 vectors were synthesized in a simple and standardized procedure. ${ }^{18}$ LEISHDNAVAX was prepared at concentrations of $0.4,2.0$ and $4.0 \mathrm{mg} \mathrm{ml}^{-1}$ of total DNA in PBS in a controlled process with subsequent quality control at Mologen AG (Berlin, Germany). The vaccine was filled as ready-to-use solutions in injection vials and sent frozen to test facilities.

\section{Biodistribution and persistence study}

Aurigon Life Science (Tutzing, Germany) performed the in-life phase in accordance with Good Laboratory Practice (GLP) Regulations and in accordance with German animal welfare regulations. The experimental design was reviewed and approved by the local government (Government of Upper Bavaria, Maximilianstraße 39, 80538 München, Amt für Verbraucherschutz und Veterinärwesen; Registration no. AZ55.2-1542532.2-14/07, study no.: 103.261.2895).

Forty Wistar rats (20 per sex, Janvier Labs, Saint-Berthevin, France), 8 weeks of age, were allocated to single- or four-dose study groups with 10 animals each (five per sex). Animals received needle injections of $120 \mu \mathrm{g}$ LEISHDNAVAX per injection $\left(\sim 5.3 \times 10^{13}\right.$ MIDGE-Th1 vector molecules, injection volume $30 \mu \mathrm{l}$ ) i.d. at the dorsal base of tail, either once or four times in weekly intervals. Animals injected with a single dose were killed $24 \mathrm{~h}$ after administration. Four-dose groups were either killed $24 \mathrm{~h}, 14$ days or 60 days after the fourth injection. Clinical signs were recorded before, $30 \mathrm{~min}$ and $4 \mathrm{~h}$ after treatment, thereafter once daily. Twenty-four hours after injection, a modified Irwin test ${ }^{39}$ was performed on the single-dose group and on a non-treated control group to assess acute neurological toxicity of the vaccine. Throughout the study, mortality was evaluated once daily and body weight once weekly. At killing, animals were anesthetized deeply by isoflurane inhalation and blood was collected from the plexus ophthalmicus. Gross pathology was performed and samples of the following tissues were taken: blood, thigh bone marrow, brain, heart, kidneys, liver (Lobus quadratus), lymph nodes (Lnn. axillares, inguinales, mesenteriales), lung, thigh muscle, ovaries, skin of injection site, spleen and testes. To avoid cross-contamination with vector DNA single-use scalpels were applied for each sample. All other equipment was thoroughly decontaminated after each dissection. Samples were immediately frozen in liquid nitrogen and stored at $-80^{\circ} \mathrm{C}$ until processing.

Quantitative analyses of DNA vector amounts were performed at IMGM Laboratories (Martinsried, Germany). Total DNA was extracted from 
$\sim 20 \mathrm{mg}$ tissue or up to $280 \mu \mathrm{l}$ blood, respectively, using the DNeasy Blood\&Tissue Kit (Qiagen, Hilden, Germany) and stored at $-20^{\circ} \mathrm{C}$. A TaqMan-based quantitative realtime-PCR assay was established and characterized using a standard curve of LEISHDNAVAX ranging from 10 vector copies per reaction to $1.05 \times 10^{11}$ vector copies per reaction with $200 \mathrm{ng}$ genomic DNA from the livers of naive animals as background. Measurements were carried out with $200 \mathrm{ng}$ of extracted total DNA in 384 well plates with a reaction volume of $20 \mu \mathrm{l}$ on an $\mathrm{AB} 7900 \mathrm{HT}$ instrument (Life Technologies, Carlsbad, CA, USA). Primers (Eurofins Genomics, Ebersberg, Germany) and hydrolysis MGB probe (Life Technologies) were designed to detect a consensus sequence present on each MIDGE-Th1 vector. The forward primer (5'-GTCGTTAGTGAACCGTCAGATCA-3') anneals to the CMV promoter region, the hydrolysis MGB probe (5'-FAMTITATTGCGGTAGTTTATCA-NFQ-3') and the reverse primer (5'-GCACG ACTGCGTTAGCAATTTAA-3') anneal to the intron. Limit of detection and lower limit of quantification of the assay were determined at 525 copies of MIDGE-Th1 vector per reaction (that is, 2625 copies per $\mu \mathrm{g}$ total DNA). All samples of extracted DNA were measured in triplicates. MIDGE-Th1 vector copy numbers were calculated according to the LEISHDNAVAX standard curve running in parallel on each plate and expressed as copy number per $\mu \mathrm{g}$ total DNA. Acceptability criteria of measurements included standard curve coefficient of correlation $\geqslant 0.95$ and detected copy numbers of No-template-controls below the limit of detection. In addition, the s.d. of the quantification cycle values of at least two replicate measurements had to be below 0.5 , otherwise the measurement was repeated.

\section{Toxicity study in naive mice}

Assessment of vaccine toxicity. The study was performed in accordance with GLP Regulations principles and German animal welfare regulations at LPT Laboratory of Pharmacology and Toxicology, Hamburg, Germany with prior approval by LPT's institutional animal care and use commissary (study no. 26814) and by the competent authority (Behörde für Gesundheit und Verbraucherschutz, Amt für Verbraucherschutz Lebensmittelsicherheit und Veterinärwesen, Billstraße 80, 20539 Hamburg, Germany, V 11307-59100.33).

One hundred and forty BALB/C mice (70 male, 70 female) were randomized and allocated to study groups. Animals were housed individually. At first treatment mice were 44-49 days (males) or 60-65 days (females) of age with a body weight of $18.2-22.5 \mathrm{~g}$ (males) or $18.0-20.4 \mathrm{~g}$ (females). Ten animals each (five per sex) received one i.d. needle injection (volume: $25 \mu \mathrm{l}$ ) into the dorsal tail base with a dose of 10,50 or $100 \mu \mathrm{g}$ LEISHDNAVAX or the placebo (PBS). They were killed $24 \mathrm{~h}$ post injection for evaluation of acute toxic reactions. Thirty animals each receiving placebo and $100 \mu \mathrm{g}$ dose, or 20 animals each receiving $10 \mu \mathrm{g}$ and $50 \mu \mathrm{g}$ dose (injection volume: $25 \mu \mathrm{l}$ ) were injected by needle i.d. into the dorsal tail base five times in weekly intervals. Animals were killed after a recovery period of $24 \mathrm{~h}, 14$ days or 61 days (placebo and $100 \mu \mathrm{g}$ dose group only) following the fifth injection (Table 1).

Animals were observed for clinical signs including injection site reactogenicity before and $30 \mathrm{~min}$ and $4 \mathrm{~h}$ after each dosing and daily between injections. Mortality was evaluated twice daily throughout the study. Body weight of animals was recorded at day of group allocation, on the day of first dosing and three times a week thereafter. Food consumption was determined weekly and water consumption was recorded daily. Neurological screening ${ }^{40}$ and assessment of grip strength $^{41}$ was conducted on all animals $24 \mathrm{~h}$ after first dosing. Ophthalmological and auditory examinations were performed pre-dose, at the end of the treatment period and at the end of the recovery period.

For urinalysis, mice were placed in funnel cages in groups of five per sex and received $30 \mathrm{ml}$ tap water per $\mathrm{kg}$ body weight by gavage. Subsequently, urine was collected for $6 \mathrm{~h}$ and the following parameters were measured: volume, weight, $\mathrm{pH}$, specific gravity, osmolality, protein, glucose, bilirubin, urobilinogen, ketones, hemoglobin, nitrite, epithelial cells, leukocytes, erythrocytes, organisms, further constituents, crystalluria.

At killing, blood was taken for clinical biochemistry (albumin, globulin, bilirubin, cholesterol, triglycerides, creatinine, glucose, protein, urea, calcium, alanine aminotransferase, alkaline phosphatase, a-amylase, aspartate aminotransferase, creatine kinase, glutamate-dehydrogenase, $\gamma$-glutamyl-transferase, lactate dehydrogenase) and hematology (hemoglobin content, erythrocytes, leukocytes, differential blood count, reticulocytes, platelets, mean platelet volume, red cell distribution width, hematocrit, mean corpuscular volume, mean corpuscular hemoglobin, mean corpuscular hemoglobin concentration).
Gross pathological examination was conducted, organ weights were taken and samples of the following organs and tissues processed for histological examination: adrenal gland, aorta abdominalis, bone (os femoris with joint), bone marrow, brain, cecum, coagulating gland with seminal vesicle, epididymis, eye with optical nerve and Harderian gland, exorbital lacrimal gland, gall bladder, heart, skin and subcutaneous tissue of injection site, large intestine, small intestine, kidney and ureter, liver, lung, lymph nodes (mandibular, mesenteric), mammary gland, muscle, sciatic nerve, esophagus, ovary, pancreas, pituitary gland, prostate, salivary glands, spinal cord, spleen, sternum, stomach, testicle, thymus, thyroid, tongue, trachea, urinary bladder, uterus and vagina.

Histological examination was performed on samples of all animals with the highest expected burden, that is, after receiving five injections of each $100 \mu \mathrm{g}$ LEISHDNAVAX and $24 \mathrm{~h}$ of recovery, and the respective placebo group as control. Moreover, the immunologically relevant organs thymus, spleen and lymph nodes as well as the skin at the injection site of all animals of all groups were examined histologically. In general, tissue samples were fixed in 7\% buffered formalin (eyes in Davidson's solution), embedded in paraffin, sections prepared and routinely stained with haematoxylin-eosin.

Samples from mice receiving five times a dose of 10 or $50 \mu \mathrm{g}$, respectively, were scheduled for histologically examination only in case of vaccine-related findings in the group receiving five times $100 \mu \mathrm{g}$, or if gross pathology revealed vaccine-related changes. As there were no respective findings, these samples were not histologically examined.

Biologic activity of the vaccine lot and assessment of antibodies against dsDNA. In all, $100 \mathrm{BALB} / \mathrm{c}$ mice (50 male, 50 female) were randomized and allocated to satellite study groups of the toxicity study resembling the repeated-dose treatment schedule (Table 1). At first treatment, animals were 44-49 days (males) or 60-65 days (females) of age with a body weight of 17-19.3 g (males) or 17-18.4 (females). At study termination, blood samples were taken and serum obtained for enzyme-linked immunosorbent assay to test for antibodies against vaccine antigens and for radioimmunoassay to test for antibodies against dsDNA. These analyses were performed under non-GLP Regulations conditions.

LEISHDNAVAX-specific antibodies were detected performing an enzyme-linked immunosorbent assay as previously described ${ }^{22}$ with minor modifications. Plates (Nunc MaxiSorp, Thermo Scientific, Roskilde, Denmark) were coated per well with $100 \mu \mathrm{l} \mathrm{of} 5 \mu \mathrm{g} \mathrm{ml}^{-1}$ antigen-mix (KMP11, CPA, CPB, P74, TSA 1:1:1:1:1) in PBS (Fisher Scientific, Paisley, UK). Recombinant proteins were obtained from Proteogenix, Oberhausbergen, France (CPA, CPB, P74, TSA) or were kindly provided by Professor $C$ Jaffe (KMP11). Antigen mix was assembled at LPT. Plates were incubated overnight at $4{ }^{\circ} \mathrm{C}$, then washed three times with wash buffer $(0.05 \%(\mathrm{v} / \mathrm{v})$ TWEEN in PBS) and subsequently blocked with assay diluent $(5 \%(\mathrm{w} / \mathrm{v})$ bovine serum albumin (Sigma Aldrich, St Louis, USA) in PBS) for $1 \mathrm{~h}$ at room temperature. Plates were washed three times with wash buffer and $100 \mu \mathrm{l}$ per well of 1:50 diluted serum samples were added. The plates were incubated for $2 \mathrm{~h}$ at room temperature and subsequently washed five times with wash buffer. Hundred micolitre per well of anti-mouse lgG-HRP (Conc.: $11.3 \mathrm{mg} \mathrm{ml}^{-1}$ ), (Sigma Aldrich) were added at a 1:5000 dilution and plates were incubated for $2 \mathrm{~h}$ at room temperature. After washing five times developer solution containing 3,3',5,5'-tetramethylbenzidine (Sigma Aldrich) was added and the reaction stopped by adding acid solution when the color developed. Absorbance was measured at $450 \mathrm{~nm}$.

To assess the induction of an immune response against dsDNA a radioimmunoassay was performed at IBL International GmbH (Hamburg, Germany) using a kit for detection of anti-dsDNA antibodies (IBL International). In brief, $25 \mu \mathrm{l}$ of serum sample was mixed with $150 \mu \mathrm{l}$ of ${ }^{125}$ I-labeled dsDNA tracer and incubated at $37^{\circ} \mathrm{C}$ for $60 \mathrm{~min}$. Subsequently, $1 \mathrm{ml}$ of cold ammonium sulfate solution was added to the sample followed by vortexing. Tubes were centrifuged $(15 \mathrm{~min}$ at $1500 \mathrm{~g})$ and supernatant was removed. Radioactivity was counted using a gamma counter and the dsDNA binding capacity was calculated according to a standard curve.

\section{Evaluation of vaccine tolerability in mouse models of} experimental VL

Experiments on infected animals were carried out under UK Home Office license PPL70/6997 following local ethical approval by the London School of Hygiene \& Tropical Medicine and the Royal Veterinary College, London.

Parasite and animal maintenance. BALB/CAnNCrl $(\mathrm{H} 2 \mathrm{~d}), \mathrm{C} 57 \mathrm{BL} / 6 \mathrm{~J}(\mathrm{H} 2 \mathrm{~b})$ and Rag-1 (B6) KO mice (Charles River, Margate, UK) were maintained 
under specific pathogen-free conditions in individually ventilated cages and exposed to $12 \mathrm{~h}$ light- $12 \mathrm{~h}$ dark cycles. Standard rodent diet (RM No 1 Expanded) and de-ionized water were supplied ad libitum. L. donovani (strain MHOM/ET/67/HU3) was maintained in Rag-1 (B6) KO mice and amastigotes harvested from spleens of infected animals $>40$ days after infection.

Infection and treatment schedule. Female BALB/C and C57BL/6 mice (68 weeks of age at the start of experiments) were infected by injecting $2 \times 10^{7}$ freshly harvested $L$. donovani amastigotes intravenously into a tail vein as described. ${ }^{42}$ Following infection, animals were sorted into groups of three to five mice per cage and two cages assigned to each treatment group. Groups of mice received either one, two or three injections of LEISHDNAVAX containing $20 \mu \mathrm{g}$ DNA/antigen (corresponding to $100 \mu \mathrm{g}$ total DNA) or PBS, administered in volumes of $25 \mu$ i.d. at the base of the tail using 29G single-use needles (BD Microfine Plus Insulin Syringes). The first dose was administered 7 days after infection and repeat doses in 7-day intervals. Groups of mice were killed 7 days after having received the last dose of LEISHDNAVAX or PBS. In a further experiment in C57BL/6 mice additional groups were killed 29 days after the last of a total of three doses of LEISHDNAVAX or PBS.

Determination of efficacy and tolerability parameters. Mouse weights were recorded prior to the first dose of treatments administered and in weekly intervals thereafter. The injection site was monitored following administration of treatments and animals were observed daily by trained staff for the whole duration of the experiments. Mice were humanely killed by exsanguination under terminal anesthesia and blood collected by cardiac puncture. Livers and spleens were removed and their weight recorded. Tissue impression smears were prepared, fixed in 100\% methanol and stained in $10 \%$ Giemsa. Parasite burden was determined microscopically and Leishman-Donovan Units calculated by the formula number of parasites per host cell nucleus $\times$ organ weight in $\mathrm{mg}$, as described previously. ${ }^{43}$ Serum was harvested from blood stored overnight at $4^{\circ} \mathrm{C}$ by centrifugation at $1500 \mathrm{~g}, 4^{\circ} \mathrm{C}$ for $15 \mathrm{~min}$ and stored at $-80^{\circ} \mathrm{C}$ Biochemical analysis of standard serum parameters was carried out by LABOKLIN GmbH\&Co.KG (Bad Kissingen, Germany). For histology, organs were fixed in $10 \%$ neutral buffered formalin, embedded in paraffin and routinely stained with hematoxylin and eosin. Histological data were evaluated in blinded fashion.

\section{Statistical methods}

Data from the repeated-dose toxicity study in naive mice were analyzed using Student's $t$-test for numerical functional tests $(P \leqslant 0.01)$, Dunnet's multiple $t$-test for body weight, food consumption, hematology, clinical biochemistry and organ weights $(P \leqslant 0.01)$ and Fisher's exact test for histology $(P \leqslant 0.05)$, respectively.

Toxicity data of the biodistribution study were evaluated as follows: parameters of the Irwin test were analyzed by Mann-Whitney U-test $(P \leqslant 0.05)$ and normality of body weight data by Shapiro-Wilks test. In case of normality, an analysis of variance was performed with post hoc Dunnett's test for multiple comparisons; otherwise, a non-parametric Kruskal-Wallis test with post hoc Dunnett's test was employed $(P \leqslant 0.05)$.

IgG levels were statistically analyzed using GraphPad Prism 5 (GraphPad Software Inc., La Jolla, USA). Normality of data was tested with Shapiro-Wilk test prior to applying either two-tailed Student's $t$-test or Mann-Whitney test to analyze differences between means of two groups $(P \leqslant 0.05)$.

To evaluate tolerability of the vaccine in infected mice, comparisons between three or more groups were made by one-way analysis of variance followed by Bonferroni's multiple comparison's test with comparison between PBS and vaccine treated groups. Comparisons between two groups were made by an unpaired $t$-test assuming Gaussian distribution (GraphPad Prism 6). A $P$-value of $<0.05$ was considered statistically significant.

\section{CONFLICT OF INTEREST}

$\mathrm{OR}, \mathrm{DO}, \mathrm{AE}$ and $\mathrm{CJ}$ are employees and MS is Chairman of the Executive Board of Mologen AG. CH is employee of IMGM Laboratories GmbH. AW is employee of LPT $\mathrm{GmbH} \&$ Co. KG. MOLOGEN AG owns a patent for the MIDGE-Th1 vector (PCT/ DE02/03798P74). These affiliations do not alter the authors' adherence to Gene Therapy policies on sharing data and materials. FJS declares no conflict of interest.

\section{ACKNOWLEDGEMENTS}

We thank the LEISHDNAVAX consortium for helpful discussions, MOLOGEN AG's production and QC department for manufacturing the vaccine, Shantanabha Das for providing the Leishmania antigen ELISA protocol and Charles Jaffe for providing recombinant KMP11. This work was funded by the European Commission as part of the 7th Framework Programme (\#223189).

\section{REFERENCES}

1 Alvar J, Velez ID, Bern C, Herrero M, Desjeux P, Cano J et al. Leishmaniasis worldwide and global estimates of its incidence. PLoS One 2012; 7: e35671.

2 WHO. Control of the leishmaniases. Report of a meeting of the WHO Expert Committee on the Control of Leishmaniases, 22-26 March 2010. World Health Organization: Geneva, Switzerland, 2010

3 Alvar J, Croft SL, Kaye P, Khamesipour A, Sundar S, Reed SG. Case study for a vaccine against leishmaniasis. Vaccine 2013; 31(Suppl 2) B244-B249.

4 Kaye P, Scott P. Leishmaniasis: complexity at the host-pathogen interface. Nat Rev Microbiol 2011; 9: 604-615.

5 Ulmer JB, Donnelly JJ, Parker SE, Rhodes GH, Felgner PL, Dwarki VJ et al. Heterologous protection against influenza by injection of DNA encoding a viral protein. Science 1993; 259: 1745-1749.

6 Wang R, Doolan DL, Le TP, Hedstrom RC, Coonan KM, Charoenvit Y et al. Induction of antigen-specific cytotoxic T lymphocytes in humans by a malaria DNA vaccine. Science 1998; 282: 476-480.

7 Carvalho JA, Rodgers J, Atouguia J, Prazeres DM, Monteiro GA. DNA vaccines: a rational design against parasitic diseases. Expert Rev Vaccines 2010; 9: 175-191.

8 US Food and Drug Administration. Guidance for Industry. Considerations for Plasmid DNA Vaccines for Infectious Disease Indications. 2007.

9 WHO Annex 1: Guidelines for assuring the quality and non-clinical safety evaluation of DNA vaccines. Technical Report Series: 2007; 941.

10 Sheets RL, Stein J, Manetz TS, Andrews C, Bailer R, Rathmann J et al. Toxicological safety evaluation of DNA plasmid vaccines against HIV-1, Ebola, Severe Acute Respiratory Syndrome, or West Nile virus is similar despite differing plasmid backbones or gene-inserts. Toxicol Sci 2006; 91: 620-630.

11 Sheets RL, Stein J, Manetz TS, Duffy C, Nason M, Andrews C et al. Biodistribution of DNA plasmid vaccines against HIV-1, Ebola, Severe Acute Respiratory Syndrome, or West Nile virus is similar, without integration, despite differing plasmid backbones or gene inserts. Toxicol Sci 2006; 91: 610-619.

12 Ferraro B, Morrow MP, Hutnick NA, Shin TH, Lucke CE, Weiner DB. Clinical applications of DNA vaccines: current progress. Clin Infect Dis 2011; 53: 296-302.

13 European Medicines Agency. CPMP/BWP/3088/99: Note for guidance on the quality, preclinical and clinical aspects of gene transfer medicinal products. London, 2001.

14 Oliveira PH, Mairhofer J. Marker-free plasmids for biotechnological applicationsimplications and perspectives. Trends Biotechnol 2013; 31: 539-547.

15 Moreno S, Lopez-Fuertes L, Vila-Coro AJ, Sack F, Smith CA, Konig SA et al. DNA immunisation with minimalistic expression constructs. Vaccine 2004; 22 1709-1716.

16 Chen ZY, He CY, Meuse L, Kay MA. Silencing of episomal transgene expression by plasmid bacterial DNA elements in vivo. Gene Ther 2004; 11: 856-864.

17 Dietz WM, Skinner NE, Hamilton SE, Jund MD, Heitfeld SM, Litterman AJ et al. Minicircle DNA is superior to plasmid DNA in eliciting antigen-specific CD8+ T-cell responses. Mol Ther 2013; 21: 1526-1535.

18 Schirmbeck R, Konig-Merediz SA, Riedl P, Kwissa M, Sack F, Schroff M et al Priming of immune responses to hepatitis $B$ surface antigen with minimal DNA expression constructs modified with a nuclear localization signal peptide. $J \mathrm{Mol}$ Med 2001; 79: 343-350.

19 Zheng C, Juhls C, Oswald D, Sack F, Westfehling I, Wittig B et al. Effect of different nuclear localization sequences on the immune responses induced by a MIDGE vector encoding bovine herpesvirus-1 glycoprotein D. Vaccine 2006; 24: 4625-4629.

20 Galling N, Kobelt D, Aumann J, Schmidt M, Wittig B, Schlag PM et al. Intratumoral dispersion, retention, systemic biodistribution, and clearance of a small-size tumor necrosis factor-alpha-expressing MIDGE vector after nonviral in vivo jetinjection gene transfer. Hum Gene Ther Methods 2012; 23: 264-270.

21 Endmann A, Oswald D, Riede O, Talman EG, Vos RE, Schroff M et al. Combination of MIDGE-Th1 DNA vaccines with the cationic lipid SAINT-18: Studies on formulation, biodistribution and vector clearance. Vaccine 2014; 32: 3460-3467.

22 Das S, Freier A, Boussoffara T, Oswald D, Losch FO, Selka M et al. ModulaR MULTiantigen T CELL EPITOPE-ENRIChed DNA vaccine against human leishmaniasis. Sci Transl Med 2014; 6: 234ra56.

23 Bankoti R, Stager S. Differential regulation of the immune response in the spleen and liver of mice infected with leishmania donovani. J Trop Med 2012 2012: 639304 . 
24 Parker SE, Monteith D, Horton H, Hof R, Hernandez P, Vilalta A et al. Safety of a GM-CSF adjuvant-plasmid DNA malaria vaccine. Gene Ther 2001; 8: 1011-1023.

25 Imboden M, Shi F, Pugh TD, Freud AG, Thom NJ, Hank JA et al. Safety of interleukin-12 gene therapy against cancer: a murine biodistribution and toxicity study. Hum Gene Ther 2003; 14: 1037-1048.

26 Brave A, Gudmundsdotter L, Sandstrom E, Haller BK, Hallengard D, Maltais AK et al. Biodistribution, persistence and lack of integration of a multigene HIV vaccine delivered by needle-free intradermal injection and electroporation. Vaccine 2010; 28: 8203-8209.

27 Doukas J, Morrow J, Bellinger D, Hilgert T, Martin T, Jones D et al. Nonclinical biodistribution, integration, and toxicology evaluations of an $\mathrm{H} 5 \mathrm{~N} 1$ pandemic influenza plasmid DNA vaccine formulated with Vaxfectin(R). Vaccine 2011; 29: 5443-5452.

28 Tuomela M, Malm M, Wallen M, Stanescu I, Krohn K, Peterson P. Biodistribution and general safety of a naked DNA plasmid, GTU-MultiHIV, in a rat, using a quantitative PCR method. Vaccine 2005; 23: 890-896.

29 Vilalta A, Mahajan RK, Hartikka J, Rusalov D, Martin T, Bozoukova V et al. I. Poloxamer-formulated plasmid DNA-based human cytomegalovirus vaccine: evaluation of plasmid DNA biodistribution/persistence and integration. Hum Gene Ther 2005; 16: 1143-1150.

30 Dolter KE, Evans CF, Ellefsen B, Song J, Boente-Carrera M, Vittorino R et al. Immunogenicity, safety, biodistribution and persistence of ADVAX, a prophylactic DNA vaccine for HIV-1, delivered by in vivo electroporation. Vaccine 2011; 29: 795-803.

31 Nafissi N, Slavcev R. Construction and characterization of an in-vivo linear covalently closed DNA vector production system. Microb Cell Fact 2012; 11: 154

32 Nafissi N, Alqawlaq S, Lee EA, Foldvari M, Spagnuolo PA, Slavcev RA. DNA ministrings: highly safe and effective gene delivery vectors. Mol Ther Nucleic Acids 2014; 3: e165.

33 Smith LR, Wloch MK, Ye M, Reyes LR, Boutsaboualoy S, Dunne CE et al. Phase 1 clinical trials of the safety and immunogenicity of adjuvanted plasmid DNA vaccines encoding influenza A virus H5 hemagglutinin. Vaccine 2010; 28: 2565-2572.

34 Vasan S, Schlesinger SJ, Huang Y, Hurley A, Lombardo A, Chen Z et al. Phase 1 safety and immunogenicity evaluation of ADVAX, a multigenic, DNA-based clade C/B' HIV-1 candidate vaccine. PLoS One 2010; 5: e8617.
35 Halstead SB, Mahalingam S, Marovich MA, Ubol S, Mosser DM. Intrinsic antibodydependent enhancement of microbial infection in macrophages: disease regulation by immune complexes. Lancet Infect Dis 2010; 10: 712-722.

36 Broker $\mathrm{M}$, Kollaritsch $\mathrm{H}$. After a tick bite in a tick-borne encephalitis virus endemic area: current positions about post-exposure treatment. Vaccine 2008; $\mathbf{2 6}$ : 863-868.

37 Beck Z, Prohaszka Z, Fust G. Traitors of the immune system-enhancing antibodies in HIV infection: their possible implication in HIV vaccine development. Vaccine 2008; 26: 3078-3085.

38 Lehmann J, Enssle KH, Lehmann I, Emmendorfer A, Lohmann-Matthes ML. The capacity to produce IFN-gamma rather than the presence of interleukin-4 determines the resistance and the degree of susceptibility to Leishmania donovani infection in mice. J Interferon Cytokine Res 2000; 20: 63-77.

39 Irwin S. Comprehensive observational assessment: la. A systematic, quantitative procedure for assessing the behavioral and physiologic state of the mouse. Psychopharmacologia 1968; 13: 222-257.

40 Gad SC. A neuromuscular screen for use in industrial toxicology. J Toxicol Environ Health 1982; 9: 691-704.

41 Meyer OA, Tilson HA, Byrd WC, Riley MT. A method for the routine assessment of fore- and hindlimb grip strength of rats and mice. Neurobehav Toxicol 1979; 1: 233-236.

42 Nicoletti S, Seifert K, Gilbert IH. N-(2-hydroxypropyl)methacrylamide-amphotericin B (HPMA-AmB) copolymer conjugates as antileishmanial agents. Int J Antimicrob Agents 2009; 33: 441-448.

43 Bradley DJ, Kirkley J. Regulation of Leishmania populations within the host. I. the variable course of Leishmania donovani infections in mice. Clin Exp Immunol 1977; 30: 119-129.

(c) (i) $(-)$ This work is licensed under a Creative Commons Attributioncc) NonCommercial-NoDerivs 4.0 International License. The images or other third party material in this article are included in the article's Creative Commons license, unless indicated otherwise in the credit line; if the material is not included under the Creative Commons license, users will need to obtain permission from the license holder to reproduce the material. To view a copy of this license, visit http:// creativecommons.org/licenses/by-nc-nd/4.0/ 